\title{
The Creative Thinking in the Art Design Education
}

\author{
Liu yijie, Zhang shu \\ Wuhan University of Science and Technology, Art Design College, Wuhan, Hubei, China \\ 308864991@qq.com,3609599@qq.com
}

\begin{abstract}
TA qualified design person must have a rich knowledge of humanities in addition to specialty basic knowledge and professional skills. Only in this way can we realize the peopleoriented design belief from the perspective of science and technology as well as the value of existence. Meanwhile, the author introduces he International and domestic practices in this aspect, and also expounds his own apperceptions. Education

Index Terms - Art Design, Humanistic Quality, Design

\section{Introduction}

Art design expresses a kind of culture in people's new life with the combination of art and science, which embodies the humanistic quality of the designer.

It is the key accountabilities of education to lay emphasis on the training of students 'humanistic qualities. Talents school conveying to the society should know and understand the culture, history, philosophy, religion except grasping necessary professional knowledge and skills. The subtle influence and impact of this knowledge can guide thinking and solving problems from the perspective of science and technology, what's more, it takes overall consideration of human and the value of existence, paying attention to human, the living environment of human and the future of human, which can truly achieve people-oriented design ideas.
\end{abstract}

\section{Status of International Art Design Education}

European modern design movement, represented by the Bauhaus, has been fit the American developed commercial design culture after spreading to the United States. With the constant effort of generations of designers and design educators, American modern art design education system is generally established and it also cultures generations of design masters exceling their own masters, like Robert Venturi, Cesar Pelli, Michael Graves etc. The age of these masters extremely emphasizes the rational-oriented internationalism prevailing, however, the themes expressed in their design ideas and works appear to be such a focus on the history, tradition, human beings, humanistic spirit in the future, which gets the recognition and praise of the world as well as affected the design education in United Stated.

American Zero Program and National Standard for Arts Education are thought-provoking. The Soviet's successful launching of satellite before 1957 surprises the United States a lot and the whole country uproars and considers the reason. They researched the project called Zero Program in Harvard Graduate School of Education. After the 20 years research of hundreds of scientists, they draw the conclusion that the lagging behind of art education leads to the lagging behind of space technology. In 1994, the administration of President Bill Clinton puts forward a new education law that makes art, history, language the core of basic education course as mathematics and nature science, and formulates the National Standard for Art Education. As Mr Qian xuesen said, Scientists, whose knowledge structure should contain art, are not artisan. National Standard for Arts Education pushed the American modern design education to a higher level. It puts forward request for the higher education and also pays attention to basic education with far look. Its fundamental purpose is to clear the impact art education on students' integrated development and the construction of a civilized society. It stresses the reasonable connection between disciplines, striving to achieve the overall education; makes art history, culture, ethnic background as the basis of art course, emphasizing the varieties of art education; emphasizes on the effective use of modern science and technology, accurate understanding the relations among technological means, artistic techniques and artistic pursuit; providing the implementation and evaluation of art education with serious academic criterion and measures.

Take the interior design education for example. American FLDER was founded in the 70s and the guiding ideology is gradually incline to perfect with decades of years development and the efforts of design masters with humanistic thought. The emphasis of American interior design education is not only the professional knowledge but the ability of comprehensive thinking. They believe that one of the functions of undergraduate education is to form a knowledge society. The FLDER standards stipulate that a complete set professional education of interior design should be a balance system, providing with cultural education with broad knowledge as well as the professional knowledge must master. FLDER put forward eight kinds of content in professional learning: :1)the cultivation of art foundation and creativity;2)theoretical basis;3)interior design;4)technical expertise;5)design presentation skills;6)knowledge of professional pratice;7)art and design history;8)research capabilities. And the eight classes is subdivided into 40 projects.

From American National Standard for Arts Education and FLOER standards, we can achieve the following knowledge : The extreme expansion of material desire and the resulting spirit crisis remind Americans their insufficient attention to humanistic education, so they vigorously strengthen the proportion of humanistic curriculum in school education. It is easy to see from National Standard for Arts Education that the United States authorities clearly affirm the"

impact of art education on students' integrated development and the construction of a civilized society in the form of law, and make the history, culture, ethnic backgrounds as the basis of art course stressing the varieties of art education. FLDER standards emphasize more on the ability of 
integrated thinking than professional knowledge. Designers should know how to consider situations like when the designer is in face of special environment, when designing for special ones like disadvantaged groups and for special purpose like heritage protection.

Comparing American art and design education system with Germany Bauhaus, we will find that they not only reflect the progress of time and technology but the greater advancement is their paying attention to humanistic spirit.

\section{Status of Domestic Art Design Education}

Chinese education and art design education is also undergoing profound changes with the influence of international environment. The previous ignoring of humanistic quality education has draws great attention of the department of education. The ministry of education has make important instructions to higher education to request colleges to attach importance to the construction and development of humanities and social science majors and further improves the recognition of position and important role of humanities and social science in promoting nation development and social progress. In order to effectively promote students' humanistic quality without excessively adding students' schoolwork burden, and carry out humanistic quality education in the education process to impart knowledge and educate people, the ministry of education issued Several Opinions on Strengthening College Students' Cultural Quality Education. The Opinions point out that strengthening cultural quality education embodies a new kind of education thought and ideas, rather than a education mode or classification. So the institutions of higher education should realize the harmonious development of knowledge, capacity and quality to improve the view of talents, recognizing that strengthening cultural quality education is an important part of high-quality talent cultivation. Cultural quality education must be throughout the whole process of college education to realize the education optimization and finally achieve the goal of teaching education, management education, service education and environmental education.

Strengthening cultural quality education basically has the following several ways and methods: combining the first class with the second class; make cultural quality education throughout professional education; strengthening the construction of campus cultural environment and improving campus cultural atmosphere; carrying out various forms of social practices activities etc. It emphatically point out that "there are rich humanistic spirit and scientific spirit included in professional course and practice course. Teachers should consciously make the humanistic spirit and scientific spirit throughout professional education when teaching professional class, fully tapping and develop the subtle role of professional class to cultural quality cultivation, to truly realize teaching education. Meanwhile, cultural quality related contents should be mixed into professional course teaching, which can learn professional courses, and at the same time improve their own cultural quality. "Famous universities like Beijing University, Tsinghua University and Huazhong University of Science and
Technology have made some beneficial attempt in this aspect in the first place. They have opened special lecture and forum with rich humanities contents; added cultural and historical courses; recommending culture and history related extracurricular reading books; strengthening the construction of campus cultural environment, through which they rich the students' humanistic knowledge to some degree, improve their humanistic quality and construct the campus humanity atmosphere. All of these play an important role in improving integrated quality of students. In the atmosphere of whole country paying attention to humanities education, art design education must lay emphasis on the cultivation of humanistic quality.

\section{Enlightments of Advance Experience at Home and Abroad}

Advanced international and domestic experience gives us a lot of enlightments.

First, reposition art design education

In the current education system, art design education is conducted according to two models. One is in comprehensive university, professional art academy and $\mathrm{m}=$ normal colleges and schools, and the other is in sorts of engineering schools. The former lays particular stress on aesthetics and basic training of art while the latter stresses on training of technology in different majors and professional skills. We can see this from their different courses. Art design disciplines are artificially separated because of the enrollment system of separating art from science. Thus, students enrolling in Fine Art College by liberal art examination can't achieve well technology and technical training, while students enrolling in engineering college by science and engineering examination can't achieve well training of art theory and foundation.

Facing this problem, we should change the way of thinking, break the academic boundaries and unify art design education. No matter in engineering school or art school, the education objects and teaching methods should be judged by the same standard. This can avoid the deviation in students accepting knowledge as well as measure the teachers and teaching level of various schools, meanwhile, the students can get rational allocation. In the settings of specific curriculum, we should break the current restricting method that art academy should set technology and professional skill related courses in art academy, and more fine art foundation course in the design major of engineering colleges.

Second, increase the teaching contents of traditional Chinese culture, classical literature and art

Historical traditional culture, classical culture and art are the important part of humanistic knowledge. It is the essential skill to ensure the creativity of designers in a sense in both east and west. We should add course on this aspect to modern design education and increase the teaching effort on this aspect. In specific teaching method, we can adopt the way of lecture, group research and traditional teaching. We should attach skills and pay more attention to the ideology and the embodied artistic conception. Guide the students to lay effort 
on extensive and profound, digest and master when studying Chinese traditional culture and classic literature

Third, actively learning new science and technology

The ultimate implement of humanistic curriculum can never ignore science and technology. In the developed countries like United States, basic art education is given high attention to not fall behind the development of times, for example, environmental science, building materials and construction, and physics, biology and chemistry. The students should learn and master new science and technology and express the work by high-tech materials and tools when studying and realizing traditional arts and humanities knowledge. Take the architectural design for example. We should be familiar with new material, especially the ecological material to design excellent works integrating art, environment protection and science.

Forth, increase the contents and patterns of practice

Now, we emphasize on academical teaching too much. But, we trend to formalize practice. Halfhearted teaching and careless learning can neither improve students' practical ability nor enhancing theoretical knowledge. In fact, the necessary practical course is essential to art design that is with strong application properties. The teacher can make the student do targeted work and make it product in the market. This is initiative practice teaching mode, and can fundamentally change the bad effect caused by past passive practice teaching. Design colleges should cultivate and train students with superior teaching quality, design philosophy and teaching attachments to reflect the superior cultural attainment from their design work and satisfy challenges and demands of market and society development. This is the true success of design education.

\section{References}

[1] Zheng Shuyang and Song Limin, etc., "environmental art design and performance techniques," Hubei: Fine Arts Publishing House, 2002.

[2] Wan Zheng, "interior design", Sichuan: Fine Arts Publishing House, 2005.

[3] HE Zhi Park and Jiang Min, "art education", People's Publishing House, 2001.

[4] Tom Anderson, "Art For Life", Hunan: Fine Arts Publishing House, 2009.

[5] Wei Zhiyuan, "Suhomlinski pedagogy (on)," Culture and Art Publishing House, 2013.

[6] Sternberg Williams, "Sternberg educational psychology", Machinery Industry Press, 2012 